\title{
Metabolic Pathway
}

National Cancer Institute

\section{Source}

National Cancer Institute. Metabolic Pathway. NCI Thesaurus. Code C18611.

An elaboration of the known steps and interactions for the metabolism of a compound. 